Research Notes

\title{
Efforts to Know the Rate at which Students Analyze and Synthesize Information in Science and Social Science Disciplines: A Multidisciplinary Bio-Communication Study
}

\author{
${ }^{1}$ Deni Darmawan, ${ }^{2}$ Yadi Ruyadi, ${ }^{3}$ Wamaungo Juma Abdu and ${ }^{4}$ Achmad Hufad \\ ${ }^{1}$ Department of Instructional Technology, \\ Faculty of Education, Universitas Pendidikan Indonesia, Indonesia \\ ${ }^{2}$ Department of Citizenship Education, \\ Faculty of Social Sciences Education, Universitas Pendidikan Indonesia, Indonesia \\ ${ }^{3}$ Institute for Research and Community Services, Universitas Pendidikan Indonesia, Indonesia, Indonesia \\ ${ }^{4}$ Department of Nonformal and Continuing Education, \\ Faculty of Education, Universitas Pendidikan Indonesia, Indonesia
}

\author{
Article history \\ Received: 16-07-2017 \\ Revised: 07-08-2017 \\ Accepted: 23-08-2017 \\ Corresponding Author: \\ Wamaungo Juma Abdu, \\ Institute for Research and \\ Community Services, \\ Universitas Pendidikan \\ Indonesia, Indonesia \\ Email: raisehope@hotmail.com
}

\section{Introduction}

This research note is based on empirical findings which focused on the effort to discover the speed at which university students process information during class sessions. In an effort to know the rate at which information is processed, a laboratory experiment was conducted to answer academics and educators' curiosity concerning information processing among students.

\begin{abstract}
Information processing is difficult to observe by most people because it involves self monitoring of one's thinking. The process under which the cognitive functions is influenced by the rate at which different people analyze and synthesise information. However, though this is true, a measure of the speed in which information is processed is still new within the Indonesian perspective. Currently, there is little or no research on this aspect. In this regard, the present research note briefly explains a research on speed with which students process instructional or classroom information; in both sciences and social science disciplines of senior high school and or universities. The behavioral and performance tendencies displayed by students have not been verified in a concrete and measurable manner. It is therefore, upon this background that we picked interest to scientifically study the rate at which information is processed among students within the Indonesian perspective in an effort to discover the rate at which analysis and synthesization of instructional information in social and science disciplines is conducted. This study was multidiscipline one and new in nature regarding speed of information processing within senior high school and or university students in Indonesia. It integrates neural aspects, information and communication technologies, combined with instructional technology together with biological components to establish how students learn and interpret concepts in their day today classroom sessions, hence lying within the range bio-communication, health communication and of course instructional communication in education. The methodology and tools used in the present study were the Laboratory Experiment method and Electroencephalography- a method that involves monitoring of the electrical functions of the brain, including information processing among learners.
\end{abstract}

Keywords: Analysis and Interpreting Information, Bio-Communication, Information Processing, Instructional Communication in Education, Synthesis
With the rapidly growing use of information and communication technologies information has become more accessible (Wiemers, 2014) and disturbing on how to determine or construct truth out of it in the most shortest time possible because obtainable information is growing at such an accelerated rate (Wiemers, 2014). This has prompted educators to ask themselves about the human cognitive development in relation to information 
processing. It is important to rationally explore and explain the performance of the human brain.

Studies of early cognitive development have led researchers to clarify on the developing mind as something competent, active, and insightful from a very early age (Springer and Deutch, 1993).

In a study on the development of students abilities it has been discovered that there is no sufficient support regarding quick processing of information by the left and right hemispheres of the students' brain (Pope, 1989). Several researchers have attempted to explain how fast certain parts of the brain work and in a series of studies conducted by these researchers, the sample is the students of social discipline and science discipline in higher education. It is important to rationally explore and explain this intrapersonal phenomenon of human brain.

The present study finds new findings that explain the phenomenon of bio-communication and information processing speed of 18-27 years old students' (university students'). According to the laboratory-based data, the phenomenon of information processing begins with the process of observation, feeling, understanding and action.

\section{Research Methodology}

This study employs Mixed Methodology (Brannen, 1993) consisted of Laboratory Experiment and Electroencephalography measurement of instructional information processing speed. The sample of the study is students from science and social disciplines. Data is analyzed using Amplitude measurement of the Electroencephalography computer display (Ernest).

\section{Findings and Discussion}

\section{The Phenomenon of Instructional Communication Behavior of 18-27 years old Students before Treatment}

At this stage of the study, the researcher investigates individual students from both social and science disciplines. The field observation shows that at this range of age, the behaviors of the individuals are stable; in that their observation, feeling and tendency to act are well-controlled and well-organized. The stimulus given in the treatment is essentially similar with that given for individuals in younger range of age (Hall, 1993). The hypothetical bio-communication behaviors of individuals in the studied group of age do no show significant differences in the social discipline and the science discipline groups. The analysis shows a difference in visual observation of objects between the two groups of students (ICA, 1995). This visual impression is the factor that affects students' rapid thinking. The visual recognition of objects is said to proceed through a sequence of three types of representation: Brightness changes and two-dimensional; spatial and view point or sketch is called 2.5 dimension; three-dimensional representation (Jain and Aggarwal, 1979).

The tendencies found in hypothetical biocommunication behaviors of individuals in this group of age show that the individuals tend to find the form and style of learning that suit their path of expectation and aspiration. If their learning styles successfully bring the individuals closer to achievement, these bio-communication behaviors will become the basis for the students to act and build their career path. However, this is merely an observation of psychological phenomenon (Hall, 1993). Therefore, the researcher conducts a laboratory experiment, with the aids from neurologists and medical experts.

Research is conducted to find evidence of biocommunication behaviors. It is found that there are differences in the speed, direction, completeness and stability of behaviors for each individual in different range of age. From this analysis, the researcher constructs the following system of bio-communication behaviors.

Based on the laboratory experiment, it is concluded that the findings on the bio-communication behaviors that affects the psychological behaviors in communication process are accountable and can be proven through analysis and investigation of behaviors displayed by specific parts of the brain. The form, direction and speed of bio-communication behaviors; which consist of observation, feeling, understanding and tendency to act, are different for each individual from different age groups. In short, the preparation, process and result of this laboratory experiment can be used as the input for further discussion on the emergence of new branch of communication discipline; i.e., the biocommunication. Particularly for the field of education and other related fields, this finding is important for analysis and development of communication strategy and approach; including for intra/interpersonal communication, psychology of communication, sociology of communication, communication technology and educational communication.

There is evidence that the basis to criticize the behaviors of individuals who have undergone a communication or education process has always been psychological (Applbaum, 1973). With the finding of bio-communication behaviors, this study will at least broaden our insight and may become a foundation to analyze behavioral changes as a result of communication and learning processes. The findings and experiment in this study are also expected to enrich the process of communication development in the future. The following table displays the comparison of university students' right and left hemispheres of brain's speed, in science and social disciplines.

When the students perform analytical thinking process, it should be accompanied by synthesize thinking process. An individual will be able to think positively and productively if he is able to do both 
analytical and synthesis thinking processes quickly. In other words, there are specific parts of the brain working to support each other.

The interaction in an instruction process needs media and tools to present the thinking and ideas in a way that is interesting and not burdensome to students (Gagne, 1985). Multimedia-computer-based instruction, which adopts information and communication technology, should be designed based on a more complex and balanced thinking processes (Pope, 1989). Roger von Oech as cited in Dryden and Vost (2003) states that we are capable of having forms of thinking which include conceptual thinking, analytical thinking, speculative thinking, right-brain thinking, critical thinking, foolish thinking, convergent thinking, weird thinking and such many other forms of thinking.

It is expected that the students are able to demonstrate all these kinds of thinking through the implementation of information and communication technology-based learning; in this case, there is learning to use multimedia computer in the form of drilling, tutorial, simulation and games controlled by bio-communication process.

Bio-Communication of 18-27 Years old Students: An Information Stimulus Treatment in Information Technology-Based Instruction in Social Sciences Disciplines

The next finding deals with the phenomenon of biocommunication process occurring in the right-brain and left-brain of the students, visible on these specific parts through Alpha $(\alpha)$ and Beta (B) wave records during the treatment of learning activities using information technology-based (multimedia) instruction for Social discipline students. Based on the observation and discussion with Dr. Siti Aminah (neurologist), reaction in students' brains begins very well in the specific part of Occipital (Occ), both on the right and the left hemispheres, as evidenced by the Alpha wave of $15-16 \mathrm{~Hz}$ in brain's speed to receive and transform messages. This speed is higher than that of students in lower level of education; this difference is assumed to be due to the age factor.

This finding provides a foundation for further description of how bio-communication occurs in the brain (in both the left-brain and the right-brain), formulated in the form of learning activities of observation, feeling, understanding and tendency to act. In the experiment, each activity in social students' brain is recorded through EEG; the result of which is described as follows.

\section{During Observation}

Bio-communication observed in university students of social discipline, who received the treatment of learning based on information technology, is reflected in the record of beta (ß) wave speed of $15-16 \mathrm{~Hz}$ while receiving and transforming instructional information. This biocommunication activity occurs when the students perform the learning activity of observing still pictures (Devito, 1996). The beta wave is observed on all specific parts of left-brain and right-brain. However, in the specific part of Occipital (O), i.e., the part of brain that serves the function of observation in both the left-brain and the right-brain, the speed of the beta wave is not evenly distributed. The record of this bio-communication phenomenon is shown in Table 1, in which the overall beta wave is $15-16 \mathrm{~Hz}$, except for the Occipital, while observing still pictures.

Similar bio-communication phenomenon also occurs when the students perform information technology-based learning activity of observing moving pictures (displayed through multimedia computer). The beta wave which represents the communication activity has a speed of 15$16 \mathrm{~Hz}$ in receiving and transforming information in specific parts of the brain. The speed of beta wave is also not distributed evenly in the specific part of Occipital, for both the left-brain and the right-brain. The record of this activity is shown in Table 1 , in which the overall Beta is $15-16 \mathrm{~Hz}$, except for the Occipital area, during the observation of moving pictures.

While the students observing still text and moving text presented through multimedia computer (information technology-based learning), it is recorded that the bio-communication phenomenon occurs with beta wave speed of $15-16 \mathrm{~Hz}$ on all specific parts of leftbrain and right-brain. Similar phenomenon as before is observed, in which the specific part of Occipital (which serves the function of observation) shows reduced speed of beta wave. The record of this phenomenon is presented in Table 1; in which the overall beta wave speed is $15-16 \mathrm{~Hz}$, except in the Occipital during the observation of still text. During the observation of moving text, it is recorded that the beta wave speed is $15-16 \mathrm{~Hz}$ in receiving and transforming information. The record is shown in Table 1, in which the overall Beta is $15-16 \mathrm{~Hz}$ during the observation of moving text.

\section{While Feeling}

The EEG record of university students of Social discipline during the information technology-based learning (Stephen 1996) shows that beta (ß) wave activity occurs on all specific parts of the brain (Frontal, Parietal, Occipital, Central, Parasagital and Temporal) for both the left-brain and the right-brain, with the speed of receiving and transforming information between 15$16 \mathrm{~Hz}$. This condition is found when the students perform learning activity of "feeling heroism". The record is shown in Table 1, in which the overall Beta is 15-16 Hz during the activity of "feeling heroism". Similar bio-communication process is also found when the students perform the learning activity of "feeling greatness". It is represented by the overall beta wave activity in all specific parts of the left-brain and the right-brain. The record of this activity is shown in Table 1 , in which the overall Beta is $15-16 \mathrm{~Hz}$ during the activity of "feeling greatness". 
Table 1. Information processing phenomenon in university students' brain before treatment (Science and social disciplines)

\begin{tabular}{ll}
\hline Research subject & The phenomenon of instructional information processing in the left and right hemispheres of the brain \\
\hline University students & Social students' left brain analysis ability is lower than Science students' left brain analysis ability \\
a. & Science students' left brain analysis ability is lower than Social students' left brain analysis ability \\
b. & Social students' right brain synthesis ability is lower than Science students' right brain synthesis ability \\
c. & Science students' right brain synthesis ability is lower than Social students' right brain synthesis ability \\
d. & Science students' left brain analysis ability is lower than Social students' left brain analysis ability \\
e. & Science students' right brain synthesis ability is lower than Social students' right brain synthesis ability \\
f. & Social students' left brain analysis ability is higher than Science students' right brain synthesis ability \\
g. & Science students' left brain analysis ability is similar with Science students' right brain synthesis ability \\
h. &
\end{tabular}

\section{While Understanding}

The next findings of bio-communication occurring during information technology-based learning for social discipline students are found through analysis of beta wave activities with the speed of receiving and transforming information of $15-16 \mathrm{~Hz}$ in the overall areas of the left-brain and the right-brain (including Frontal, Parietal, Occipital, Central, Parasagital and Temporal areas). These findings are found when the students perform the learning activity of understanding information presented during information technology-based learning, particularly when they restate the text that they have understood. The record of this finding is shown in Table 1, in which the overall beta wave is $15-16 \mathrm{~Hz}$ for understanding while restating still text. Similar condition is also found when the students perform the learning activity of restating moving text that they have understood. This phenomenon is reflected in the beta wave activity of $15-16 \mathrm{~Hz}$ in receiving and transforming information in all specific parts of the left-brain and the right-brain.

\section{Tendency to Act}

Another finding of bio-communication process is found when the students of social discipline perform learning activity of tendency to act; i.e., performing simple movements during the lesson, such as pressing the keyboard keys during the lesson. The finding is explained through the activity of beta ( $($ ) wave with the speed of $15-16 \mathrm{~Hz}$ in all specific parts of the left-brain and the right brain (Frontal, Parietal, Occipital, Central, Parasagital and Temporal areas). This finding based on the EEG record is shown in Table 1, in which the overall Beta is $15-16 \mathrm{~Hz}$ while the students perform familiar simple movements.

Similar phenomenon is also found when students from any social science discipline perform learning activity with a tendency to act; i.e., performing simple movements during the lesson, such as pressing keyboard keys that they are unfamiliar (Syam, 2001). The record of this phenomenon is presented in Table 1, in which the overall Beta is $15-16 \mathrm{~Hz}$ while the students perform simple movements that they are unfamiliar with. All movement coordination is basically controlled by the language function of the brain (Chauchard, 1983; Pope, 1989), as represented in the following figure.
The process of bio-communication behaviors occurring in the left-brain and the right-brain of university students of Science discipline after the treatment of information technology stimulus.

The recording of brain activities begins from the preparation stage. Before the university students of science discipline is treated with the stimulus, the phenomenon of bio-communication is first observed in terms of which specific part of the brain the communication process occurs. Based on the observation of alpha $(\alpha)$ wave, as one of the brainwaves present in the EEG recording of brain activation, it is found that the speed of the brainwave to receive, process and transform information into electromagnetic signals and distribute the information to other specific areas of the brain is $14-15 \mathrm{~Hz}$.

Then, through the treatment of information technology-based learning process (using multimedia computer) containing instructional information for Science discipline, several bio-communication phenomena are found in specific parts of the left-brain and the right-brain; including the learning activities of observation, feeling, thinking, understanding, listening, seeing-hearing-doing and tendency to act. The findings are discussed as follows.

\section{During Observation}

The finding recorded during the learning process of Science discipline student also provides an explanation of how the left-brain and the right-brain communicate through their specific parts. The record shows that the communication activity is represented by the beta wave activity with the speed of receiving and transforming information between $14-15 \mathrm{~Hz}$. The activity of the beta wave is found in all specific parts of the brain, such as the Frontal (F), Parietal (P), Occipital (Occ), Central (C), Parasagital and Temporal (T) areas, in both the left-brain and the right-brain. This phenomenon of biocommunication occurs when the students observe still picture, moving picture, still text and moving text presented through information technology-based learning (multimedia computer). The record of each phenomenon is presented in Table 2, in which the overall Beta is $14-15 \mathrm{~Hz}$ for each observation activity of still picture, moving picture, still text and moving text. 
Table 2. The process of observing bio-communication phenomenon of the left-brain and the right-brain using Electroencephalography (EEG) in students of science discipline

\begin{tabular}{lll}
\hline No & Treatment of information technology-based science learning & University level \\
\hline & Basic pattern & of alpha ( $\alpha$ ) wave in Occ \\
1. & Looking at still pictures (observation) & Overall beta 14-15 Hz \\
2. & Looking at moving pictures (observation) & Overall beta 14-15 Hz \\
3. & Looking at still text (observation) & Overall beta 14-15 Hz \\
4. & Looking at moving text (observation) & Overall beta 14-15 Hz \\
5. & Reading still text (thinking) & Overall beta 14-15 Hz \\
6. & Reading moving text (multimedia thinking) & Overall beta 14-15 Hz \\
7. & Restating still text (understanding) & Overall beta 14-15 Hz beta 14-15 Hz \\
8. & Restating moving text (understanding) & Overall beta 14-15 Hz \\
9. & Listening to music (listening) & Overall beta 14-15 Hz \\
10. & Listening to teacher's explanation while looking at computer display (feeling) \\
11. & Seeing, reading and listening (multimedia) & Overall beta 14-15 Hz \\
12. & Having opinion on the “volume of pyramid" (feeling) & Overall beta 14-15 Hz \\
13. & Having opinion on the volume of pyramid (feeling) & Overall beta 14-15 Hz \\
14. & Pressing the X key (simple kinesthetic) and lowercase key & Overall beta 14-15 Hz \\
15. & Pressing the PrtSc key &
\end{tabular}

\section{While Feeling}

The phenomenon of bio-communication occurring in the left-brain and the right-brain is also found when the students perform learning activity of "feeling the conformity of teacher's explanation with the presented material" during the information technology-based learning (using multimedia computer). It is also found when the students perform learning activity of "feeling differences of what they see" during the lesson. The specific parts of the brain that show bio-communication activities, represented by beta ( $($ ) wave with the speed of 14-15 Hz, include the Frontal (F), Parietal (P), Occipital (Occ), Central (C), Parasagital and Temporal (T) areas. The record of these phenomena are shown in Table 2, in which the overall Beta is $14-15 \mathrm{~Hz}$ for the activities of "feeling the conformity of teacher's explanation with the presented material" and "feeling the presence of difficulties and differences".

\section{While Understanding}

The bio-communication phenomena of Science discipline students are found when they perform learning activities of understanding still text, moving text, still pictures and moving pictures. Overall, in the specific parts of Frontal (F), Parietal (P), Occipital (Occ), Central (C), Parasagital and Temporal (T) areas, the speed of the beta wave in receiving and transforming instructional information is between 14-15 Hz. This activity of beta wave is observed in all specific areas of the left-brain and the right-brain (Frontal, Parietal, Occipital, Central, Parasagital and Temporal areas). The record of these phenomena is shown in Table 2, in which the overall Beta is $14-15 \mathrm{~Hz}$ during the activities of understanding still text, moving text, still pictures and moving pictures.

\section{Tendency to Act}

Another phenomenon of bio-communication is observed during the recording of Science students' learning activities of performing simple (basic) movements, such as pressing the " $\mathrm{A}$ " key on the computer keyboard. This phenomenon is explained by the beta wave with the speed of $14-15 \mathrm{~Hz}$ in receiving and transforming information on all specific parts (Frontal, Parietal, Occipital, Central, Parasagital and Temporal areas) of the left-brain and the right-brain. The record of this phenomenon is presented in Table 2, in which the overall beta is $14-15 \mathrm{~Hz}$ during the learning activity of performing familiar basic movements. Similar phenomenon is also found during the recording of Science students' learning activities of performing simple movement of pressing a key of computer keyboard that they are unfamiliar with (for instance, the key "PrtSc"). The speed of the beta wave is recorded to be 14-15 Hz. The record is shown in Table 2, in which the overall beta is $14-15 \mathrm{~Hz}$ during the learning activity of performing unfamiliar basic movements.

The findings of the study indicate that students' ability to process instructional information, including in higher education level, is determined by harmonious thinking. Harmonious thinking is characterized by the presence of beta brainwave in the electroencephalography recording. As has been found, the association process of the students requires harmonious or systematic thinking. Through systematic thinking, the students are expected to be able to empower the association parts of their brain. Lawrence et al. (2004) state association represents events, people and places formed when the brain disconnect or connect different kinds of information, especially if the connection is beneficial for the future. This view indicates that individual students will understand what they are 
learning in accordance with the ability of the two parts of their brain to associate the information in their memory, to form a conclusion about the material (knowledge) they are currently studying.

The findings of this study concerning biocommunication behaviors should be implemented in the learning process in universities, because these findings can be adopted by any students in any university. The following is the construct of the findings on bio-communication, integrated to some previous studies on communication.

\section{Conclusion}

Based on the findings and discussion in this study, the results of laboratory experiment on the speed of information processing in university students can be categorized into four phenomena. The first is the phenomenon of information processing speed during 'observation' process. The second phenomenon is the information processing when the students 'feel' what they are learning. The third phenomenon is the need to 'understand' what they are studying, seeing and processing in all specific parts of their left-brain and right-brain. The fourth phenomenon is the stage of 'tendency to act'. Out of these four phenomena, the fourth one is the most stable for the students of both Social and Science disciplines. Both groups of students experience the phenomenon in all specific parts of their right-brain and left-brain; i.e., the Frontal (F), Parietal (P), Occipital (Occ), Central (C), Parasagital and Temporal (T) areas. The information processing speed is explained by the beta brainwave with overall speed of 14-15 Hz (in observing still pictures, moving pictures, still text and moving text).

\section{Recommendation}

Instructional information processing, as found in the present study, can be optimized through the use of moving visual messages (animation) stimulus. The development of analysis and synthesis abilities can be regarded as indicators of the differences in students' leftbrain and right-brain's speed of information processing for students who study Science and those who study Social subjects. Educators are expected to develop instructional messages (information) in the context of improving students' bio-communication abilities, particularly to optimize the specific area of left and right brains, such as re-frontal, frontal, temporal, parietal, occipital and central areas.

\section{Author's Contributions}

Deni Darmawan: $\mathrm{He}$ is the main author, most of the work has been obtained from one of his studies, and some information got from his dissertation.
Yadi Ruyadi: With a background from citizenship education, Yadi provided much of the information from the social sciences perspective and he made sure this research note if finally published.

Wamaungo Juma Abdu: Is the corresponding author and contributed financially.

Achmad Hufad: Being an expert in research methods, he made sure the method used in this research note fits the study [he therefore contributed a lot to the methodology part].

\section{Ethics}

We wish to declare that all the necessary academic procedures have been followed in writing this research note and there is no plagiarism of any kind.

\section{References}

Applbaum, 1973. Strategies for Persuasive Communication. 1st Edn., Charles E. Merril Publishing Company, Ohio.

Brannen, J., 1993. Memandu penelitian kualitatif dan kuantitatif. UI Jakarta.

Chauchard, P., 1983. Bahasa dan Pikiran. 1st Edn., Kanisius, Yogyakarta.

Devito, A.J., 1996. Komunikasi antar Manusia. 1st Edn., Harper Collins Publisher Inc, New York.

Dryden, G. and V. Jeanette, 2003. Revolusi Cara Belajar. 1 st Edn., KAIFA, Bandung.

Gagne, 1985. Essentials of Learning for Instruction. 1st Edn., Dryden Press, New York.

Hall, 1993. Teori-Teori Holistik: OrganismikFenomenologis. 1st Edn., Kanisius, Yogyakarta.

Jain, R. and K.J. Aggarwal, 1979. Computer analysis of scenes with curved objects. Proc. IEEE, 67: 805-812. DOI: 10.1109/PROC.1979.11329

ICA, 1995. Instructional/developmental communication: National Communication Association (NCA), Instructional Development.

Lawrence, C.K. M. Rubin, A. Bahasa and A. Sindoro, 2004. Mengasah Otak dalam Praktek Sehari-hari, 1st Edn., Interaksara, Batam.

Pope, G. 1989. Antropologi Biologi. 1st Edn., Rajawali, Jakarta.

Springer, P. and G. Deutch, 1993. Left Brain, Right Brain. 4th W.H. Freeman and Company, New York.

Stephen, W Littlejohn. 1996. Theories of Human Communication. 1st Edn., Wadsworth Publishing Company, Belmont.

Syam, N.W., 2001. Rekonstrusi ilmu komunikasi perspetif pohon komunikasi dan pergeseran paradigma komunikasi pembangunan dalam era globalisasi: Pidato pengukuhan guru besar ilmu komunikasi, FIKOM, UNPAD.

Wiemers, R.W., 2014. Accessing, analyzingand synthesizing information. Lipscomb University. 